\title{
Strength Properties of Coated Paper with Cuminum cyminum L. and Prunus mahaleb L.
}

\author{
Ahsen Ezel Bildik Dal \\ ahsenezel.bildik@istanbul.edu.tr \\ Received: 30 April 2018 \\ Accepted: 11 June 2018 \\ DOI: $10.18466 /$ cbayarfbe.419992
}

Forest Products Chemistry and Technology, Forest Faculty, Istanbul University-Cerrahpaşa, Istanbul, Turkey

\begin{abstract}
Coating of the paper surface against to microorganism to making it suitable for food packaging is crucial in terms of improving antimicrobial properties. Cuminum cyminum L. known as cumin and Prunus mahaleb L. have the abundant chemical compound. Cumin has antiviral activity that making it proper for coating due to its various components. Mahaleb as well has rich fragrance make it eligible for sugary snacks and chocolate package. After coating with such biomaterials, thanks to varied fatty acids impart protective feature from oxidation to paper surface. It was observed that the odor of substances was trapped from paper samples. Wrapping paper selected as a base paper in this study. Cationic starch used for emulsifying the coating chemical. Cumin and mahaleb added the starch emulsion and coating suspension applied on the top pile of the paper with \# 0 drawdown bar. Coating application reduced the paper's tear index results but increase tensile and burst index results in both cases. Mahaleb gives better Cobb $_{60}$ value and bursting and tensile index and comparing to Cumin. However, cumin coated papers tensile index results in machine direction was better than mahaleb. Both natural substances are suitable material as an additive to the coating.
\end{abstract}

Keywords: Paper coating, natural pigment, mahaleb and cumin coating.

\section{Introduction}

Paper packaging products, convenient for the food industry. Paper is a natural carbohydrate polymer made from substantially cellulose. Their unique porous structure provides lightweight, durable features besides coating material could apply with ease and quickly dry. Impart antimicrobial properties to the nutrition's where contact the paper surface is field that receiving it is worth mentioning attention to various research. Coating of the paper surface making available for food contact packaging is significant in terms of favoring antimicrobial properties. As paper have hygroscopic structure, it is weak against water vapor, gases and oils. Synthetic polymers like PVA, latex etc. generally utilized for developing the barrier features of paper and paperboards. This kind of substances fill the gaps in paper and paperboards provide the density of materials. Surfaces developed by using environment-friendly renewable biodegradable materials in recent years rather than those synthetic substances [1].

Many experts have designed to test antimicrobial packaging materials against bacteria, fungi and several microorganisms. According to previous studies, due to extend the shelf life of nutrition's, essential oils could use as antimicrobial substances [2]. Cinnamon essential oil is one of them. Results showed that compared to control samples; coating with cinnamon to paper packaging surface extends the shelf life of bread [3]. In addition to essential oils, natural bioactive agents are also using as coatings $[4,5]$. These are often found on paper and board packaging applications for the food industry; Chalier et.al. shows that soy protein contains carvacrol coated papers release carvacol substance prolong with relative humidity and temperature [6]. Another material is paraffin-based coating agents that could extend the shelf life too $[7,8]$. Coated with carvacrol nanoclay-wheat gluten papers increased film barrier properties and stability during manufacturing [9]. Chitosan is natural material also and there are lots of study about ChitosanCoated Paper [10]. Evaluating the improvement of water vapor permeability of chitosan wax coated paper is one of them [11]. Coating both of the surface with the chitosan-caseinate exhibited reduction in water vapor permeability [12]. When used as a filler material, chitosan films enhanced water resistance [13]. Similar results obtained investigations [14] and [15] in terms of oil proof papers, which coated with chitosan. Besides Encapsulate with $\beta$-cyclodextrin garlic oil for packaging application subjected of another study [16]. It is proven in a study that partially control microbial degradation with silver ions [17]. All this inorganic antimicrobial efficiency achieved for food contact paper materials with coating application. Substrate or base layer controls mechanical features of the coating. Still, tensile features of coated papers depend on coating weight [18].

Besides, it is also critical to control the surface of the paper against liquids. The paper surface should absorb the coating material equally. The Cobb $_{60}$ test evaluates water absorption value by the paper sample during the test period. $\mathrm{Cobb}_{60}$ also used an indicator of the degree of 
sizing of paper [18]. After surface sizing with starch it was determined that some of strength properties of paper increased [19]. Similar results obtained from current article. Coated papers weight increases from 5 to $16 \mathrm{~g} / \mathrm{m}^{2}$ results that increase to elongation value around 5\% [12].

\section{Materials and Methods}

\subsection{Preparation of Natural Pigments}

Cumin and mahaleb bought in closed vacuum packages. Dry matter amount of powdered substances determined. Powders filtered with 100-mesh screen and kept in drying oven in $60^{\circ} \mathrm{C}$ for an hour.

\subsection{Preparing the Paper Coating Substances}

$4.5 \%(\mathrm{w} / \mathrm{w})$ of starch cooked at $95^{\circ} \mathrm{C}$, and then $5.16 \%$ $(\mathrm{w} / \mathrm{w})$ cumin and $5.21 \%(\mathrm{w} / \mathrm{w})$ mahaleb added separately when starch was cool down at $30^{\circ} \mathrm{C}$. Distilled water used in all processes. All paper surface single side coated with using \# 0 bar by coating applicator (Film coater model K202 from RK print coat instrument). The applicator speed was $3 \mathrm{~cm} / \mathrm{s}$.

\subsection{Determination of Paper Strength Properties}

Paper strength tests performed in İstanbul University, Faculty of Forestry, Department of The Chemistry and Technology of Forestry Products SEKKA Laboratory. Zwick Universal Test machine used for evaluate to bursting strength (ISO 2758) and tensile strength (ISO 1924-2). Tear strength (ISO 1974) evaluated in. Elmendorf test machine. $\mathrm{Cobb}_{60}$ results measure according to ISO 535. After kept 24 hours in the conditioning room, paper tests obtained. Standard method was ISO 287.

\section{Results and Discussion}

\subsection{Tests Results of Paper Samples}

Basis weight changes and $\mathrm{Cobb}_{60}$ results in paper samples were in Table 1 and 2 coating amounts resulted in targeted weight gain.

Table 1. Basis Weight of the Paper Samples.

\begin{tabular}{|c|c|}
\hline Coating Material & Grammage $\left(\mathrm{g} / \mathrm{m}^{2}\right)$ \\
\hline None & 50.00 \\
\hline Starch & 54.10 \\
\hline Cumin & 59.70 \\
\hline Mahaleb & 59.97 \\
\hline
\end{tabular}

Table 2. Water Absorption $\left(\mathrm{Cobb}_{60}\right)$ Results of Untreated and Treated Papers.

\begin{tabular}{cc}
\hline Coating Material & Cobb60 Value $\left(\mathbf{g} / \mathbf{m}^{\mathbf{2}}\right)$ \\
\hline None & 21.00 \\
Starch & 16.25 \\
Cumin & 15.16 \\
Mahaleb & 18.70 \\
\hline
\end{tabular}

The difference between cumin and mahalep due to the viscosity.
Table 3. Tensile Index Values of the Paper Samples.

\begin{tabular}{ccc}
\hline $\begin{array}{c}\text { Coating } \\
\text { Material }\end{array}$ & $\begin{array}{c}\text { M.D. Tensile } \\
\text { Index } \\
\text { (N.m2/g) }\end{array}$ & $\begin{array}{c}\text { C.D.Tensile } \\
\text { Index (N.m2/g) }\end{array}$ \\
\hline None & 62.16 & 32.19 \\
Starch & 61.71 & 35.06 \\
Cumin & 62.42 & 34.28 \\
Mahaleb & 63.89 & 36.74 \\
\hline
\end{tabular}

Table 4. Bursting Index and Tear Index Values of the Paper Samples.

\begin{tabular}{cccc}
\hline $\begin{array}{c}\text { Coating } \\
\text { Material }\end{array}$ & $\begin{array}{c}\text { M.D.Tear } \\
\text { Index } \\
(\mathbf{m N . m} / \mathbf{g})\end{array}$ & $\begin{array}{c}\text { C.D.Tear } \\
\text { Index } \\
(\mathbf{m N . m} / \mathbf{g})\end{array}$ & $\begin{array}{c}\text { Bursting } \\
\text { Index } \\
\text { (kPa) }\end{array}$ \\
\hline None & 4.12 & 5.12 & 75.11 \\
Starch & 3.66 & 4.85 & 79.43 \\
Cumin & 3.59 & 4.91 & 78.09 \\
Mahaleb & 3.46 & 5.01 & 79.85 \\
\hline
\end{tabular}

Coating process forms a conservative layer on the paper surface, hence coated paper gains resistance against bursting and tensile. Tear Index value reduced with coating partly because of damaged hydrogen bonding between the fibers (Table 3 and 4). Machine direction (M.D.) were less increase than cross direction (C.D.) in tensile and tear index values.

\section{Conclusion}

It could be expected that increasing treatment level with a cationic starch in the paper coating application. Starch has increased burst index properties especially Cobb $_{60}$ values itself. Although the present results indicate, mahaleb has a positive impact in terms of Cobb 60 value. In addition, the natural basic character of cumin is a sign of a suitable coating polymer. Nevertheless, despite cumin strong acidic character does not prevent their use as a coating agent. Despite Cuminaldehyde is a constituent of the cumin has antiviral properties, it should be examined for the availability of food contact materials because of the strong odor. Appear encouraging in this regard; suitability for food contact packaging of cumin could be the subject of another research. Results related to strength properties, tear index obtained for reduced by coating. Effects were generally consistent with wetting and drying process repeatedly, the nature of coating application, which destructive effect to fiber-fiber bounding. On the contrary, due to coating materials filling of the gaps in the paper, tensile index and burst index values were increased.

This study has a precaution in terms of the shelf life extension studies of nutrition. It envisaged that the cumin and mahaleb powder could successfully applied in wrapping paper in contact with food. 


\section{References}

1. Aloui, H, Khwaldia, K, Ben Slama, M, Hamdi, M, Effect of glycerol and coating weight on functional properties of biopolymer-coated paper, Carbohydrate Polymers, 2011, 10631072.

2. Rodriguez, A, Battle, R, Nerin, C, The Use of Natural Essentia Oils as Antimicrobial Solutions in Paper Packaging, Part II, Progress in Organic Coatings, 2007, 60, 33-38.

3. Rodriguez, A, Nerín, C, Batlle, R, New Cinnamon-Based Active Paper Packaging Against Rhizopusstolonifer Food Spoilage, Journal of Agricultural and Food Chemistry, 2008, 56(15), 6364 6369.

4. Han, J.H, Antimicrobial Food Packaging, Food Technology, 2000 , 54(3), 56-65

5. Velazquez, J, Antimicrobial Food Packaging, London, UK Academic Press, 2015.

6. Chalier, P, Ben Arfa, A, Guillard, V, Gontard, N, Moisture and Temperature Triggered Release of a Volatile Active Agent from Soy Protein Coated Paper: Effect of Glass Transition Phenomena on Carvacrol Diffusion Coefficient, Journal of Agricultural and Food Chemistry, 2009, 57(2), 658-665.

7. Rodriguez, A, Battle, R, Nerin, C, Determination of Fifteen Active Compounds Released from Paraffin-Based Active Packaging in Tomato Samples via Microextraction Techniques. Analytical and Bioanalytical Chemistry, 2009, 395(1) p. 203-211.

8. Rodriguez, A, Nerin, C, Battle, R, Active Paraffin-Based Paper Packaging for Extending the Shelf Life of Cherry Tomatoes, Journal of Agricultural and Food Chemistry, 2010, 58(11), 67806786.

9. Vartiainen, J, Motion, R, Kulonen, K, Ratto, M, Skytta, E, Advenainen, R, Chitosan-Coated Paper: Effects of Nisin and Different Acids in the Antimicrobial Activity, Journal of Applied Polymer Science, 2004, 94, 986-993.

10. Mascheroni, E, Chalier, P, Gontard, N, and Gastaldi, E, AntiMicrobial Effectiveness of Relative Humidity-Controlled Carvacrol Release from Wheat Gluten/Montmorillonite Coated Papers, Food Control, 2011, 22(10), 1582-1591.
11. Zhang, W, Xiao, H, Qian, L, Enhanced Water Vapour Barrier and Grease Resistance of Paper Bilayer-Coated with Chitosan and Beeswax, Carbohydrate Polymers, 2014, 30, 401-406.

12. Khwaldia, K, Basta, A.H, Aloui, H, El-saied, H, ChitosanCaseinate Bilayer Coatings for Paper Packaging Materials, Carbohydrate Polymer, 2014, 99, 508-516.

13. Dehnad D, Mirzaei H, Emam-Djomeh Z, Jafari S.M, Dadash S2.Thermal and Antimicrobial Properties of ChitosanNanocellulose Films for Extending Shelf Life of Ground Meat, Carbohydrate Polymers, 2014, 109, 148-154.

14. Kjellgren, H, Gallstedt, M, Enfström, G, Jarnström, L, Barrier and Surface Properties of Chitosan-Coated Greaseproof Paper, Carbohydrate Polymers, 2006, 65, 453-460.

15. Khwaldia, K, Physical and Mechanical Properties of Hydroxypropyl Methylcelullose-Coated Paper as Affected by Coating Weight and Coating Compositon, BioResource, 2013, $8(3), 3438-3452$

16. Ayala-Zavala, J.F, Gonzalez-Aguilar, G.A, Optimizing the Use of Garlic Oil as Antimicrobial Agent on Fresh-Cut Tomato through a Controlled Release System, Journal of Food Science, 2010, 75 398-405.

17. Fernández, A, Picouet, $P$, Lloret, E, Cellulose-Silver Nanoparticle Hybrid Materials to Control Spoilage-Related Microflora in Absorbent Pads Located in Trays of Fresh-Cut Melon, International Journal of Food Microbiology, 2010, 142(1-2), 222228.

18. Levlin, J.E, General Physical Properties of Paper and Board, Pulp and Paper Testing, Helsinki, Finland: Fapet Oy, 1999, 138-160.

19. Sönmez, S, Interactive Effects of Copolymers and Nano-Sized Pigments on Coated Recycled Paperboards in Flexographic Print Applications, Asian Journal of Chemistry, 2011, 23(6), 2609-2613. 